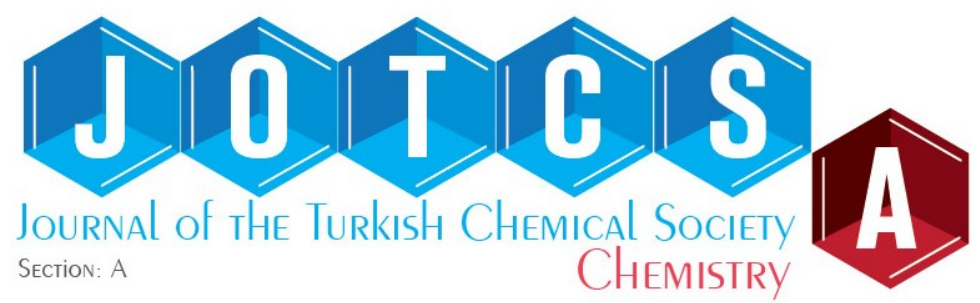

\section{Mg-Al Layered Double Hydroxide (LDH) as an Adsorbent for Removal of Itaconic Acid from Aqueous Solutions: Equilibrium and Kinetic Study}

\author{
Melisa LALIKOGLU* $\triangle$ iD \\ Istanbul University-Cerrahpasa, Faculty of Engineering, Department of Chemical Engineering, 34320, \\ Istanbul, Turkey.
}

Keywords: Itaconic acid, adsorption, layered double hydroxide.

Submitted: September 05, 2020. Accepted: December 04, 2020.

Cite this: Lalikoglu M. Mg-Al Layered Double Hydroxide (LDH) as an Adsorbent for Removal of Itaconic Acid from Aqueous Solutions: Equilibrium and Kinetic Study. JOTCSA. 2021;8(1):103-116.

DOI: https://doi.org/10.18596/jotcsa.790865.

*Corresponding author. E-mail: melisad@istanbul.edu.tr.

\section{INTRODUCTION}

Itaconic acid, also called methylene succinic acid, is an unsaturated dicarboxylic acid with the molecular formula of $\mathrm{C}_{5} \mathrm{H}_{6} \mathrm{O}_{4}$. It is used as a monomer in plastic, resin, coating, thickener, adhesive, paint, and synthetic fibers in the chemical industry. Conjugated double bonds and two carboxyl groups in the structure activate this acid for many chemical reactions such as esterification with alcohols, complexing with metal ions, anhydride production and polymerization. It can be used in the food and pharmaceutical industry as a biomonomer instead of petrochemical-based acrylic or methacrylic acid. Itaconic acid is soluble in ethanol, acetone, and water and slightly soluble in organic solvents (1). Its chemical structure is shown in Figure 1.<smiles>C=C(CC(=O)O)C(=O)O</smiles>

Figure 1: Itaconic acid's molecular structure.

Itaconic acid can be obtained by synthetic and biotechnological methods. Synthetic methods have considerable disadvantages, such as high chemical consumption and high energy requirements. Besides, in recent years, developments affecting the world, such as depleting fossil fuel reserves and global warming, reveal the importance of sustainable production. In this sense, the chemical industry has turned towards the biotechnological process for clean production via fermentation, which will ensure the use of natural resources as raw materials and minimize waste. This method has revealed a 
renewable and environmentally friendly alternative to petrochemical-based (synthetic) production (2). However, there are two main problems with fermentation technology. The first one is acid inhibition. As the amount of acid formed in the fermentation medium increases, the $\mathrm{pH}$ decreases, which causes the death of microorganisms. Therefore, the continuation of the process will be feasible by removing the acid in the medium or adding an agent to neutralize the fermentation media. Another problem is that the acid formed from fermentation is found in a dilute aqueous solution of about $10 \%(w / w)(3,4)$.

Recovery of the acid from the aqueous medium accounts for approximately $50 \%$ of the total cost. Therefore, the separation part is an essential step in the economic evaluation of the process. The development and implementation of a low cost and effective separation method will make biotechnological acid production preferable. For this purpose, many different methods have been investigated in the literature to separate carboxylic acids from their aqueous solutions (5-7). Among these methods, membrane processes $(8,9)$, electrodialysis processes $(10,11)$, crystallization processes $(12,13)$, and reactive extraction processes (14-18) have been used to remove itaconic acid from the aqueous solution. However, when these methods were compared with each other, it is possible to mention of various drawbacks. Membrane and crystallization processes are expensive processes due to high energy costs (19). Conventional solvents used in the reactive extraction method has a harmful effect on both human health and ecological balance. Besides, extraction systems have several disadvantages, such as high energy consumption and large equipment size requirement. One of the most crucial advantages of the adsorption process over the extraction is the ease of separation of the adsorbent. Magalhaes et al. conducted an economic analysis of the purification and recovery process of itaconic acid by fermentation. They indicated that the adsorption method is the most economical process compared to other separation methods (crystallization, extraction, and electrodialysis). The adsorption process is generally preferred due to its low cost, easy applicability, high efficiency, simplicity of equipment and easy regeneration of the adsorbent, and it is considered one of the promising methods (20).

The properties of adsorbent, which is to be used to separate carboxylic acids from their aqueous solutions, can be listed as having high selectivity, high adsorption capacity, being chemically and thermally stable, regenerable, biologically compatible with microorganisms, and being low-cost. In recent years, researches showed that synthetic polymeric and inorganic adsorbents had gained importance. Many modifications of adsorbent properties, such as functionality, surface area, polarity, and porosity, enable these materials to behave selectively. Thus, an effective separation can be realized (21).

Layered double hydroxide (LDH), $\left[M^{\prime \prime}{ }_{1-x} M^{\prime \prime \prime}{ }_{x}(O H)_{2}\right]^{x+}$

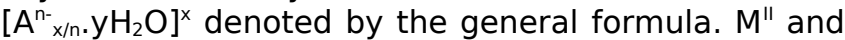
$\mathrm{M}^{\mathrm{III}}$ represent divalent and trivalent metal cations, respectively. $A^{n-}$ indicate inorganic or organic interlayer anion with the $n$ electrical charge, and $x$ defines the trivalent metal ratio $\left[\mathrm{M}^{\prime \prime \prime} /\left(\mathrm{M}^{\prime \prime}+\mathrm{M}^{\prime \prime \prime}\right)\right](22)$. It is an anionic clay classified as an inorganic nanomaterial. According to the application, layered double hydroxides can be designed in many ways with their various compositions and different synthesis methods. They are used as catalysts, additives for polymers, ion exchangers, and drug carriers (23). It has physical and chemical properties similar to clay minerals and is used as adsorbent. The most important feature of these inorganic materials; the adsorption capacity is high due to their high ion exchange capacity. Also, it is cheap and easily synthesized (24-27). In recent research, different carboxylic acids have been successfully removed from aqueous solutions using LDH (28-30).

Limited numbers of scientific studies have been conducted on separating itaconic acid from aqueous solutions by the adsorption method. Gulicovski et al. investigated the parameters affecting the adsorption of itaconic acid onto alumina (31). Magalhaes et al. reported that the adsorption process using strong basic ion exchange resin (Purolite A-500P and PFA300) was more effective and faster than crystallization and evaporation processes in the industry (32).

This study aims to separate itaconic acid from aqueous solutions by adsorption using Mg-Al-Cl LDH. Various adsorption isotherm models such as Langmuir, Freundlich, and Temkin were applied to the obtained experimental data. Adsorption behavior was kinetically investigated using pseudo-first-order, pseudo-second-order, and Elovich models.

\section{EXPERIMENTAL SECTION}

\section{Chemicals}

Aluminum chloride hexahydrate $\left(\mathrm{AlCl}_{3} \cdot 6 \mathrm{H}_{2} \mathrm{O}\right)$, magnesium chloride hexahydrate $\left(\mathrm{MgCl}_{2} \cdot 6 \mathrm{H}_{2} \mathrm{O}\right)$, and sodium hydroxide $(\mathrm{NaOH})$ were all purchased from Sigma-Aldrich (Germany). Itaconic acid was purchased from Merck (Germany). All chemicals used in experimental studies were provided as high purity products, and solution forms were prepared using deionized water.

\section{Synthesis of Mg-Al-LDH}

In our study, Mg-Al-LDH was synthesized using the co-precipitation method under an inert atmosphere at room temperature in accordance with the procedure in the literature $(33,34)$. Briefly, salt solutions of $\mathrm{MgCl}_{2} \cdot 6 \mathrm{H}_{2} \mathrm{O}(3 \mathrm{mmol})$ and $\mathrm{AlCl}_{3} \cdot 6 \mathrm{H}_{2} \mathrm{O}(1$ $\mathrm{mmol}$ ) were dissolved in $10 \mathrm{~mL}$ of deionized water 
and rapidly poured into $40 \mathrm{~mL}$ of $\mathrm{NaOH}$ solution (6 $\mathrm{mmol})$. The prepared solution in slurry form was stirred for 1 hour; after aging for 2 hours, it was subjected to centrifugation for 5 minutes, at 4500 rpm. The LDH was prepared for adsorption by drying in a vacuum atmosphere at room temperature before using.

\section{Batch Adsorption Experiments}

Among the parameters affecting the adsorption processes, adsorbent amount, time, initial acid concentration and temperature were selected and examined experimentally. Batch adsorption experiments were carried out in a $50 \mathrm{~mL}$ glass flask. First, to determine the equilibrium time (optimum time) in the adsorption of itaconic acid with LDH, 5 $\mathrm{mL}$ of acid solution with an initial acid concentration of $80.50 \mathrm{~g} \mathrm{~L}^{-1}$ onto $0.1 \mathrm{~g}$ adsorbent were added. This mixture was agitated in a Nuve Shaker ST30 thermostat bath at a constant speed (150 rpm) and temperature $(298 \mathrm{~K})$. The samples were taken from the shaker every 15 minutes and centrifuged at 4000 rpm for 10 minutes. The aqueous phase was analyzed using an automatic titrator with $0.1 \mathrm{M}$ $\mathrm{NaOH}$ solution and phenolphthalein indicator. $( \pm 0.01$ uncertainty). The point at which the acid percentage did not change with time was defined as equilibrium time. To examine the effect of adsorbent amount, experiments were carried out by adding $5 \mathrm{~mL}$ of the itaconic acid solution with a concentration of $80.50 \mathrm{~g}$ $\mathrm{L}^{-1}$ to the flasks containing $0.05-1.0 \mathrm{~g}$ of $\mathrm{LDH}$. In order to investigate effect of temperature on adsorption, experiments were conducted at three different temperatures of 298, 308, and $318 \mathrm{~K}$. For this aim, $0.1 \mathrm{~g}$ of adsorbent and acid solutions having $20.06,40.12,60.35$, and $80.50 \mathrm{~g} \mathrm{~L}^{-1}$ initial acid concentrations were investigated at these temperatures according to the experimental procedure described above.

The adsorption capacity $\left(\mathrm{q}_{\mathrm{e}}\right)$ and removal efficiency $(\mathrm{R} \%)$ was calculated using the following equations (1) and $(2)$, respectively:

$$
\begin{aligned}
& q_{e}=\frac{C_{0}-C_{e}}{M} \times V \\
& R \%=\frac{C_{0}-C_{e}}{C_{0}} \times 100
\end{aligned}
$$

where $\mathrm{C}_{0}$ represents the initial acid concentration of itaconic acid $\left(\mathrm{mg} \mathrm{L}^{-1}\right) ; \mathrm{C}_{\mathrm{e}}$ shows the equilibrium acid concentration of itaconic acid $\left(\mathrm{mg} \mathrm{L}^{-1}\right) ; \mathrm{V}$ and $\mathrm{M}$ signify the volume of solution ( $L$ ) and the amount of $\mathrm{LDH}(\mathrm{g})$

\section{RESULTS AND DISCUSSIONS}

The effects of the adsorption time, LDH amounts, initial acid concentration, and adsorption temperature changes on the adsorption efficiency were examined and reported.

\section{The Effect of Adsorption Time}

To determine the equilibrium adsorption time, the experiments were carried out at $298 \mathrm{~K}$ using an initial acid concentration of $80.50 \mathrm{~g} \mathrm{~L}^{-1}$ in the presence of 0.1 grams of the adsorbent. The results are shown in Figure 2. It was seen that the amount of acid adsorbed increased as the contact time increased over time, and the acid concentration remained constant after a certain time. Thus, the optimum equilibrium adsorption time was determined as 180 minutes.

\section{The Effect of Adsorbent Amount}

In order to examine the effect of different LDH amounts on adsorption; $0.05,0.10,0.15,0.20,0.30$, $0.40,0.50,0.60,0.80$, and $1.0 \mathrm{~g}$ of adsorbent was used with an initial acid concentration of $80.5 \mathrm{~g} \mathrm{~L}^{-1}$ at $298 \mathrm{~K}$. The experimental data were given in Table 1 and Figure 3. It was observed from Figure 3 that the adsorption capacity decreased with the amount of adsorbent increase. Previous studies in the literature explain the decrease in adsorption capacity by the presence of a large number of unsaturated active sites on the adsorbent surface (29). As shown in Table 1 , the itaconic acid removal efficiency increased from $10.8 \%$ to $69.1 \%$. 


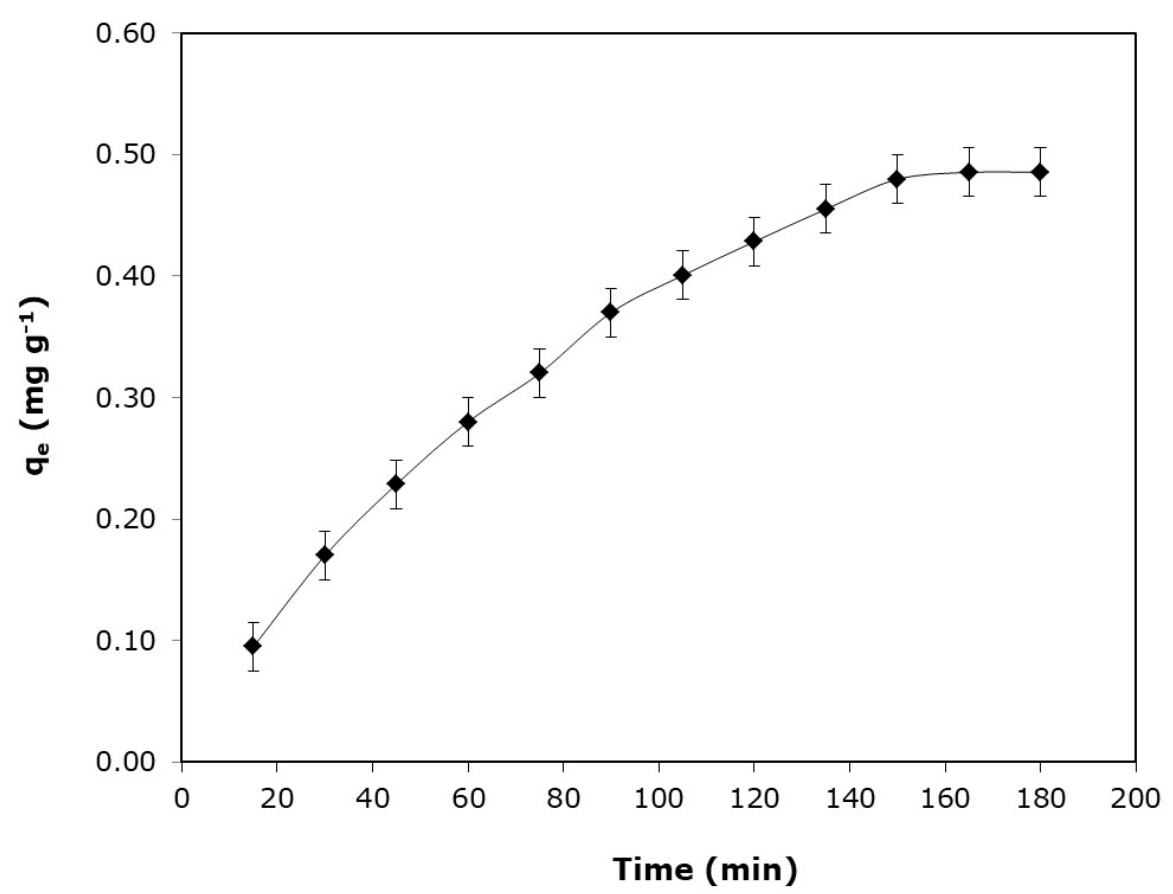

Figure 2: Equilibrium time for the adsorption of itaconic acid by LDH. $\left(\mathrm{C}_{0}=80.50 \mathrm{~g} \mathrm{~L}^{-1}, \mathrm{M}=0.1 \mathrm{~g} \mathrm{LDH}\right.$, and $\left.\mathrm{T}=298 \mathrm{~K}\right)$

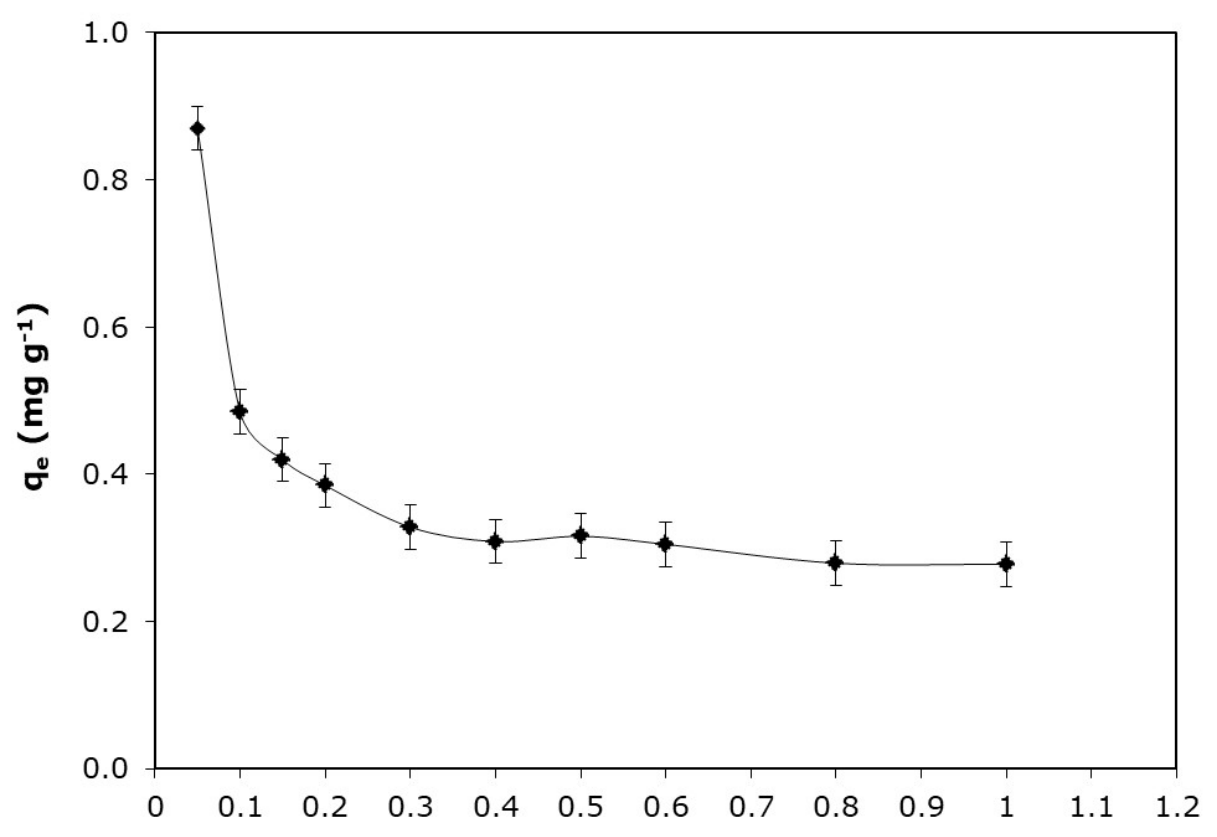

Amount of LDH ( $g$ )

Figure 3: The effect of amounts of LDH on itaconic acid adsorption. $\left(\mathrm{C}_{0}=80.50 \mathrm{~g} \cdot \mathrm{L}^{-1}, \mathrm{~T}=298 \mathrm{~K}, \mathrm{t}=180 \mathrm{~min}\right)$ 
Table 1: The effect of amounts of LDH on itaconic acid adsorption.

\begin{tabular}{|c|c|c|c|}
\hline Amount of LDH (g) & $\begin{array}{c}\text { Equilibrium } \\
\text { concentration, } \mathrm{C}_{\mathrm{e}} \\
\left(\mathrm{g} \mathrm{L}^{-1}\right)\end{array}$ & $\begin{array}{l}\text { Amount of adsorbed } \\
\text { acid, } \mathrm{q}_{\mathrm{e}} \\
\left(\mathrm{mg} \mathrm{g}^{-1}\right)\end{array}$ & $\begin{array}{c}\text { Removal efficiency } \\
(\%)\end{array}$ \\
\hline 0.05 & 71.8 & 0.870 & 10.8 \\
\hline 0.10 & 70.8 & 0.485 & 12.1 \\
\hline 0.15 & 67.9 & 0.420 & 15.6 \\
\hline 0.20 & 65.1 & 0.385 & 19.1 \\
\hline 0.30 & 60.8 & 0.328 & 24.5 \\
\hline 0.40 & 55.8 & 0.309 & 30.7 \\
\hline 0.50 & 48.9 & 0.316 & 39.2 \\
\hline 0.60 & 43.9 & 0.305 & 45.5 \\
\hline 0.80 & 35.8 & 0.279 & 55.5 \\
\hline 1.00 & 24.9 & 0.278 & 69.1 \\
\hline
\end{tabular}

The Effect of Initial Itaconic Acid Concentration To investigate the effect of initial acid concentration on adsorption, itaconic acid solution concentrations were determined as $20.06,40.12,60.35$, and $80.50 \mathrm{~g}$ $\mathrm{L}^{-1}$. The experiments were executed at three different temperatures $(298,308$, and $318 \mathrm{~K})$ and the predetermined adsorption equilibrium time with an adsorbent amount of 0.1 grams. The results of the experiments were given in Table 2 . The adsorbed acid amount $\left(q_{e}\right)$ values increased with increasing initial acid concentration.

\section{The Effect of Temperature}

The effect of temperature on the adsorption of itaconic acid onto LDH was investigated at three different temperatures of 298,308 and $318 \mathrm{~K}$, and four different initial acid concentrations (20.06, $40.12,60.35$, and $80.50 \mathrm{~g} \mathrm{~L}^{-1}$ ). The obtained experimental results were demonstrated in Figure 4. It was seen from Figure 4, the adsorption capacity increased with the increase in temperature. It was observed that the adsorption capacity increased from $0.358 \mathrm{mg} \mathrm{g}^{-1}$ to $0.485 \mathrm{mg} \mathrm{g}^{-1}$ at $298 \mathrm{~K}$, from 0.368 $\mathrm{mg} \mathrm{g}^{-1}$ to $0.630 \mathrm{mg} \mathrm{g}^{-1}$ at $308 \mathrm{~K}$, from $0.395 \mathrm{mg} \mathrm{g}^{-1}$ to $0.740 \mathrm{mg} \mathrm{g}^{-1}$ at $318 \mathrm{~K}$. As a result of these data, it was revealed that the adsorption of itaconic acid with $\mathrm{LDH}$ is an endothermic process.

\section{Adsorption Isotherms}

Adsorption isotherms are mathematical models used to explain the adsorption process. The models indicate at a constant temperature that the relationship between the amount of material adsorbed by the adsorbent and the equilibrium concentration. In this study, Langmuir, Freundlich and Temkin isotherm models were used to explain the adsorption process. Equations for the isotherm models were presented below (35):

\section{Langmuir Isotherm}

The Langmuir isotherm model is an experimental model showing that adsorption is single layer adsorption and formulated as:

$$
q_{e}=\frac{q_{0} K_{L} C_{e}}{1+K_{L} C_{e}}
$$

Linear expression of the Langmuir isotherm model can be stated as (Eq. 4):

$$
\frac{C_{e}}{q_{e}}=\frac{1}{K_{L} q_{0}}+\frac{C_{e}}{q_{0}}
$$

In this equation, $C_{e}\left(\mathrm{mg} \mathrm{L}^{-1}\right)$ shows the equilibrium concentration of itaconic acid, $q_{e}\left(\mathrm{mg} \mathrm{g}^{-1}\right)$ signifies adsorption capacity, $q_{0}\left(\mathrm{mg} \mathrm{g}^{-1}\right)$ and $K_{L}$ denotes saturation capacity and Langmuir isotherm coefficient, respectively. 
Table 2: The Effects of initial acid concentration at different temperatures $(M=0.1 \mathrm{~g}, t=180 \mathrm{~min})$

\begin{tabular}{|c|c|c|c|}
\hline $\begin{array}{c}\text { Temperature } \\
\text { (K) }\end{array}$ & $\begin{array}{c}\text { Initial acid } \\
\text { concentration, } \mathrm{C}_{0} \\
\left(\mathrm{~g} \mathrm{~L}^{-1}\right)\end{array}$ & $\begin{array}{c}\text { Equilibrium } \\
\text { concentration, } C_{e} \\
\left(g^{-1}\right)\end{array}$ & $\begin{array}{c}\text { Amount of adsorbed } \\
\text { acid, } q_{\mathrm{e}} \\
\left(\mathrm{mg} \mathrm{g}^{-1}\right)\end{array}$ \\
\hline \multirow{4}{*}{298} & 20.06 & 12.9 & 0.358 \\
\hline & 40.12 & 31.5 & 0.431 \\
\hline & 60.35 & 51.1 & 0.463 \\
\hline & 80.50 & 70.8 & 0.485 \\
\hline \multirow{4}{*}{308} & 20.06 & 12.7 & 0.368 \\
\hline & 40.12 & 29.8 & 0.516 \\
\hline & 60.35 & 48.8 & 0.578 \\
\hline & 80.50 & 67.9 & 0.630 \\
\hline \multirow{4}{*}{318} & 20.06 & 12.1 & 0.398 \\
\hline & 40.12 & 28.4 & 0.586 \\
\hline & 60.35 & 46.7 & 0.683 \\
\hline & 80.50 & 65.7 & 0.740 \\
\hline
\end{tabular}

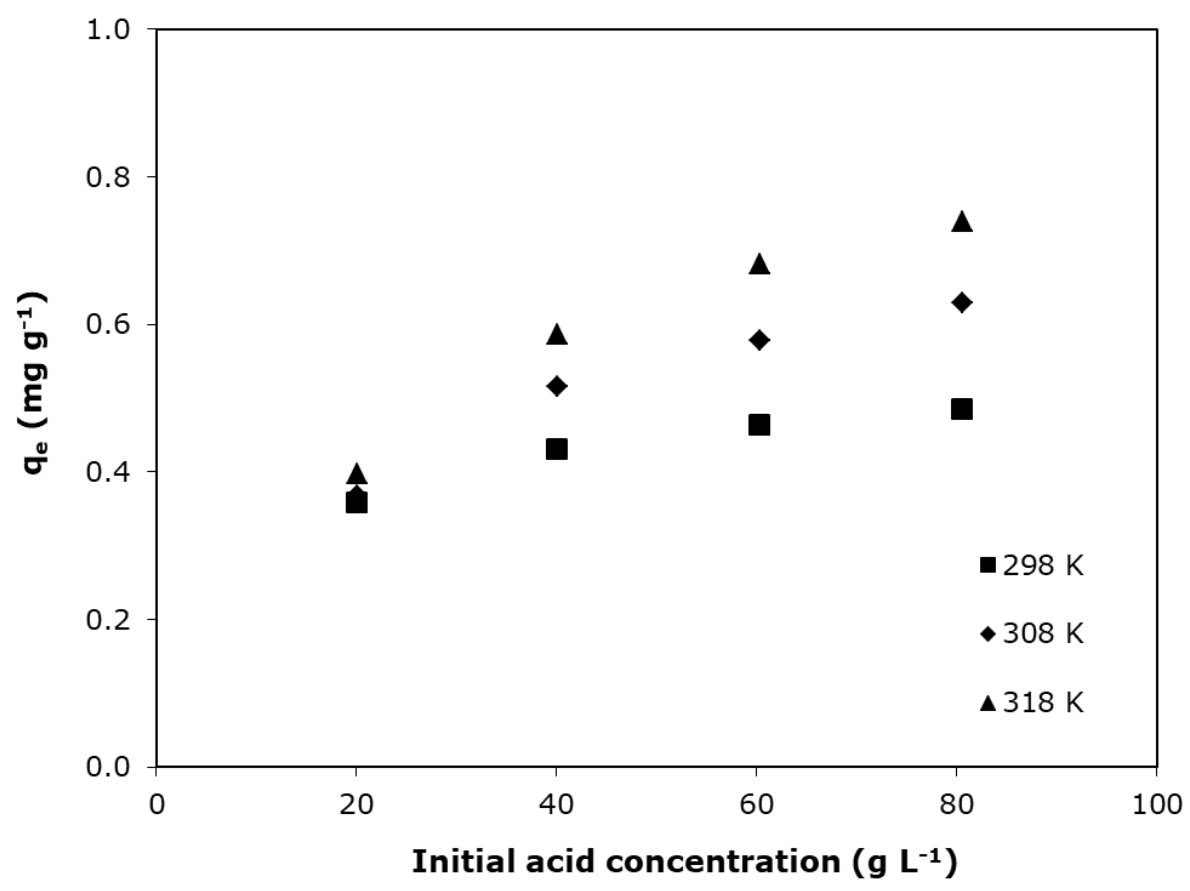

Figure 4: The effect of temperature on itaconic acid adsorption by LDH for different initial acid concentration. $(M=0.1 \mathrm{~g}, t=180 \mathrm{~min})$

Freundlich Isotherm

The Freundlich isotherm is generally used to define adsorption properties for the heterogeneous surfaces and the adsorption characteristics of adsorbents. The non-linear mathematical equation form of the Freundlich isotherm can be expressed as follows:

Equation (6) is obtained by linearizing Equation (5): 


$$
\begin{array}{r}
q_{e}=K_{f} \times C_{e}^{\frac{1}{n}} \\
\log q_{e}=\log K_{f}+\frac{1}{n} \log C_{e}
\end{array}
$$

$$
B=\frac{R T}{b}
$$

(6) The linear form of the equation of Temkin is given in Equation (9).

$$
q_{e}=B\left(\ln K_{T}\right)+B\left(\ln C_{e}\right)
$$

Freundlich coefficient related to adsorption capacity and adsorption intensity, respectively.

\section{Temkin Isotherm}

The Temkin isotherm is used to explain the adsorption behavior. It reveals that the adsorption energy in the molecular layer is a result of adsorbent-adsorbate interactions. The Temkin isotherm assumes that the decrease in adsorption energy is linear.

Temkin isotherm model equations are signified as below:

$$
q_{e}=b \ln \left(K_{T} C_{e}\right)
$$

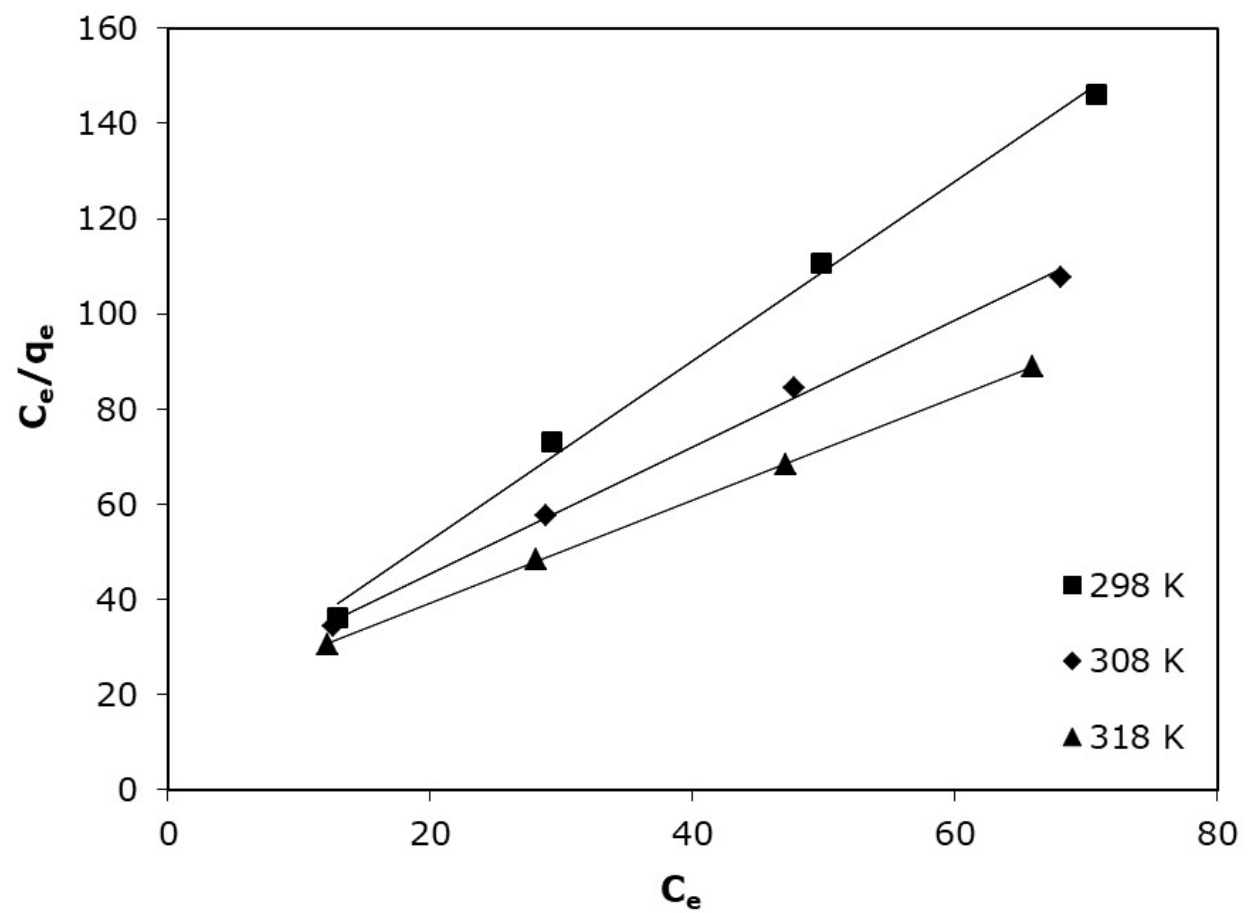

(a) 


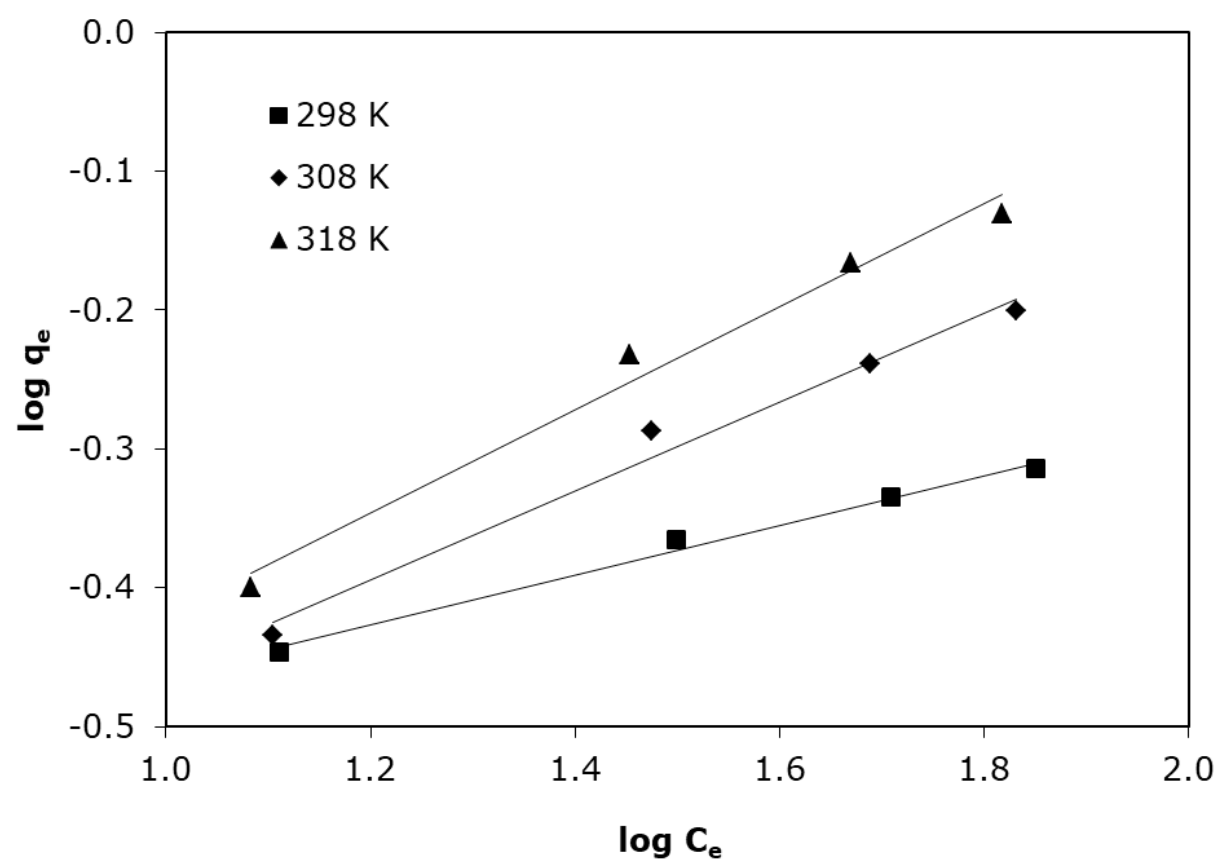

(b)

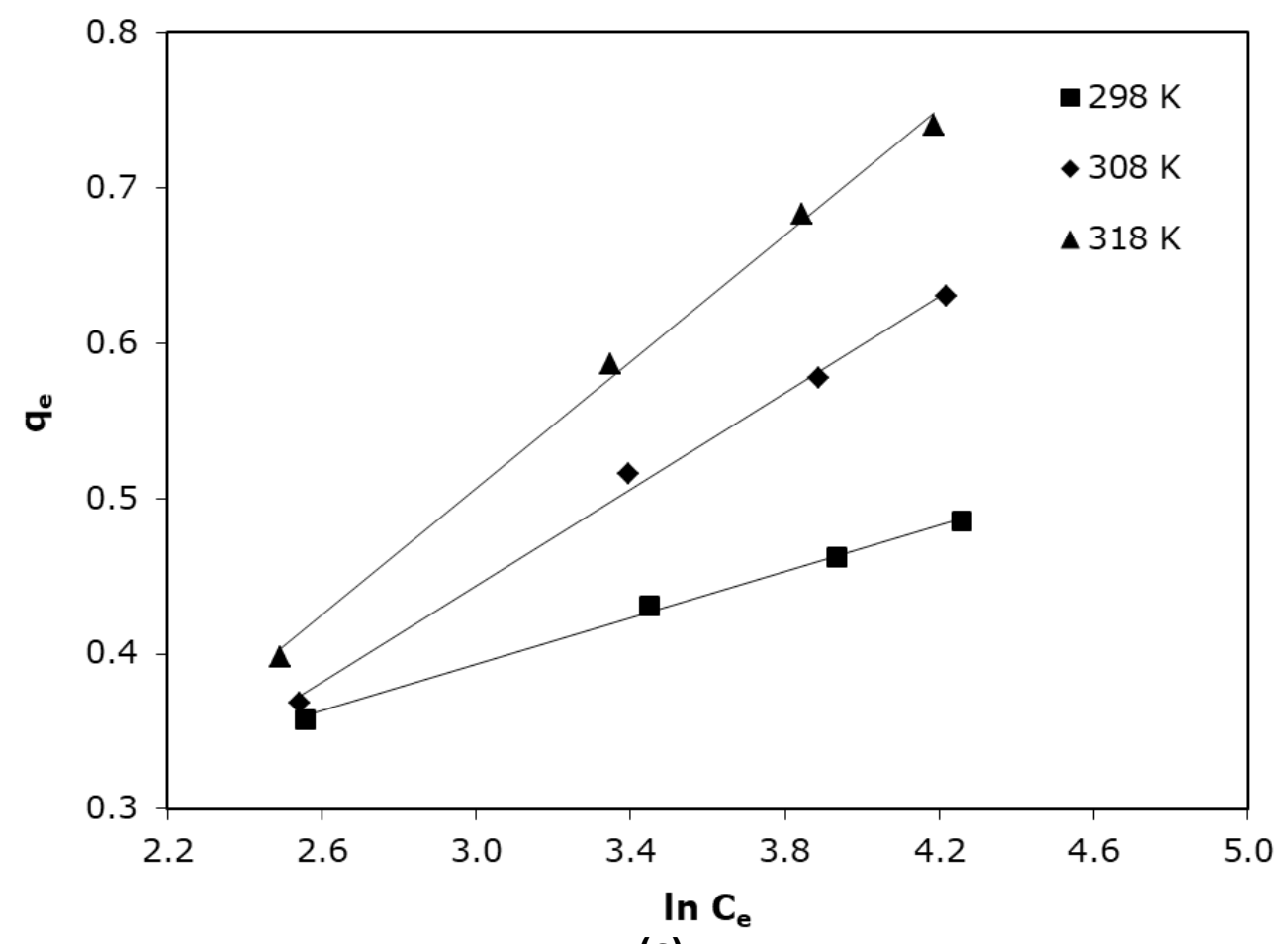

(c)

Figure 5: Equilibrium of itaconic acid adsorption onto LDH at different temperatures, (a) Langmuir isotherm; (b) Freundlich isotherm; (c) Temkin isotherm. 
Table 3: Isotherm parameters for adsorption of itaconic acid by LDH

\begin{tabular}{|c|c|c|c|c|}
\hline Isotherm & Temperature (K) & $q_{0}\left(\mathrm{mg} \mathrm{g}^{-1}\right)$ & $K_{L}\left(g^{-1}\right)$ & $\mathbf{R}^{2}$ \\
\hline \multirow{3}{*}{ Langmuir } & 298 & 0.5307 & 0.1318 & 0.9960 \\
\hline & 308 & 0.7541 & 0.0698 & 0.9972 \\
\hline & 318 & 0.9236 & 0.0618 & 0.9998 \\
\hline \multirow{4}{*}{ Freundlich } & Temperature (K) & $\mathbf{n}$ & $K_{f}\left(g^{-1}\right)$ & $\mathbf{R}^{2}$ \\
\hline & 298 & 5.58 & 0.2429 & 0.9913 \\
\hline & 308 & 3.12 & 0.1664 & 0.9833 \\
\hline & 318 & 2.69 & 0.1616 & 0.9828 \\
\hline \multirow{4}{*}{ Temkin } & Temperature (K) & B & $\mathbf{K}_{\mathrm{T}}\left(\mathbf{g ~ L}^{-1}\right)$ & $\mathbf{R}^{2}$ \\
\hline & 298 & 0.0746 & 9.6800 & 0.9970 \\
\hline & 308 & 0.1550 & 0.8716 & 0.9957 \\
\hline & 318 & 0.2037 & 0.5987 & 0.9972 \\
\hline
\end{tabular}

As shown in Table 3, the regression coefficient $\left(R^{2}\right)$ values of all the isotherm models were higher than 0.98 . So, all the isotherm models used in the study showed high compatibility with the experimental data. This situation indicated that there is more than one mechanism for the adsorption of itaconic acid by LDH (36).

\section{Adsorption Kinetics}

Explanation of the adsorption mechanism is very important for the design of the adsorption process. The kinetic models were used to reveal the adsorption mechanism. Pseudo-first-order, pseudosecond-order and Elovich kinetic models were applied to the adsorption equilibrium data to evaluate the adsorption of itaconic acid by LDH at 298 K (37). The kinetic model equations used to determine the rate of adsorption are presented as follows:

Pseudo-first-order (Lagergren) kinetic model;

$$
\log \left(q_{e}-q_{t}\right)=\log q_{e}-\frac{k}{2.303} \times t
$$

Pseudo-second-order kinetic model;

$$
\frac{t}{q_{t}}=\frac{1}{k_{2} q_{e}^{2}}+\frac{1}{q_{e}} t
$$

Elovich kinetic model

$$
q_{t}=\frac{1}{\beta} \ln (\alpha \beta)+\frac{1}{\beta} \ln (t) q_{t}
$$

$q_{e}\left(\mathrm{mg} \mathrm{g}^{-1}\right)$ : is the adsorption capacity at equilibrium, $q_{t}\left(\mathrm{mg} \mathrm{g}^{-1}\right)$ : is the adsorption capacity at any time (t), $k_{1}\left(\mathrm{~min}^{-1}\right)$ : pseudo-first-order kinetic rate coefficient, $k_{2}\left(\mathrm{~g} \mathrm{\textrm {mg } ^ { - 1 }} \mathrm{min}^{-1}\right)$ : pseudo-second-order kinetic rate coefficient,

$\alpha\left(\mathrm{mg} \mathrm{g}^{-1} \mathrm{~min}^{-1}\right)$ : is the initial adsorption rate,

$\beta$ (g mg $\mathrm{m}^{-1}$ ) adsorption capacity; is the constant of desorption.

Figure $6(a, b, c)$ gives the kinetic model plots for the $\mathrm{LDH}$, and the model parameters are represented in Table 4. 


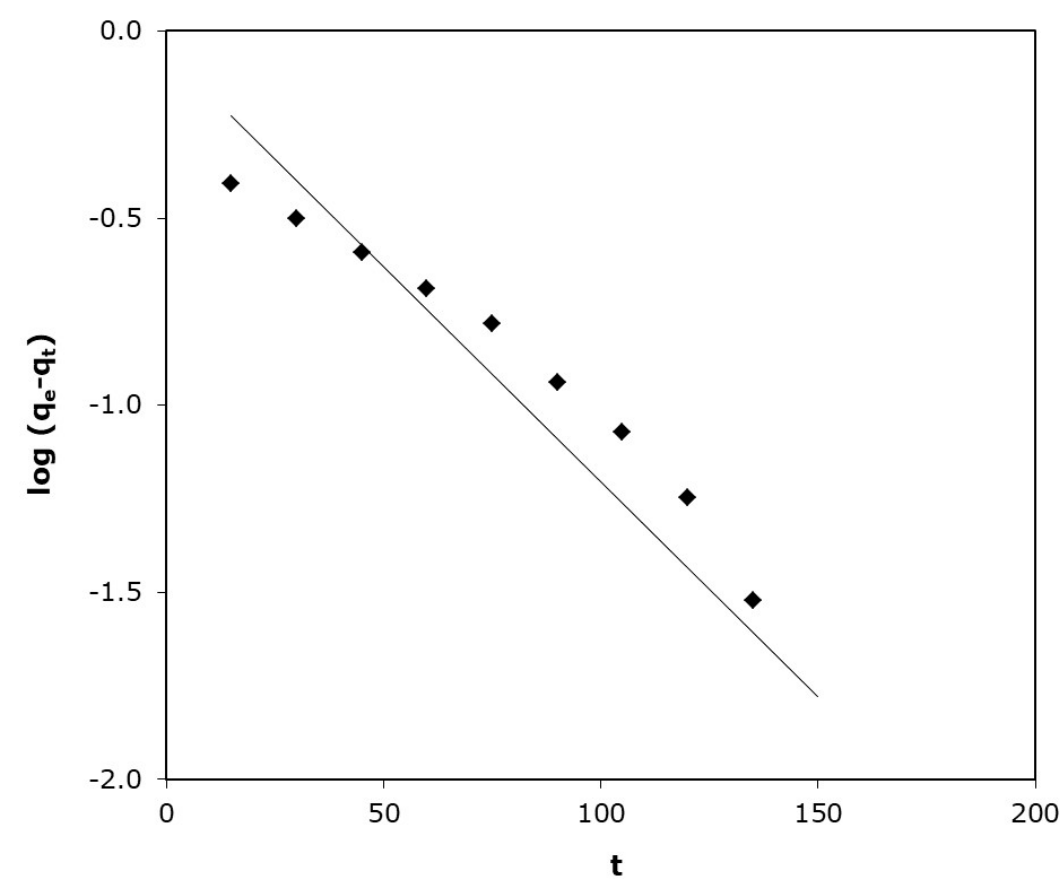

(a)

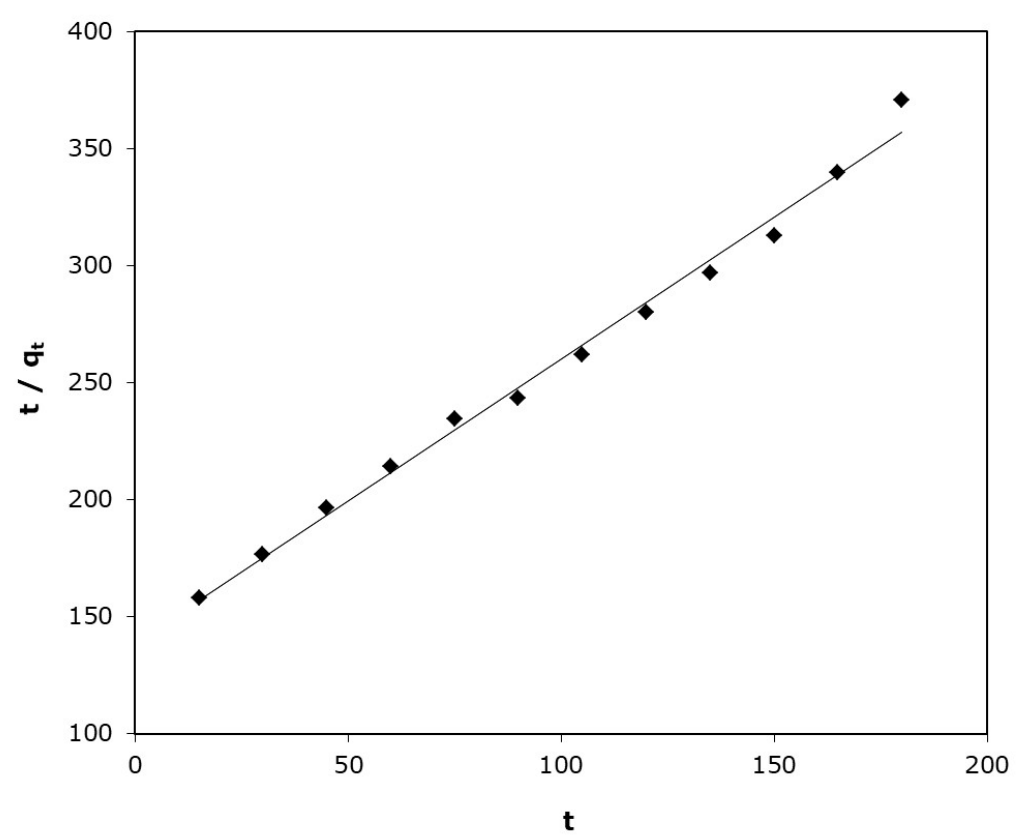

(b) 


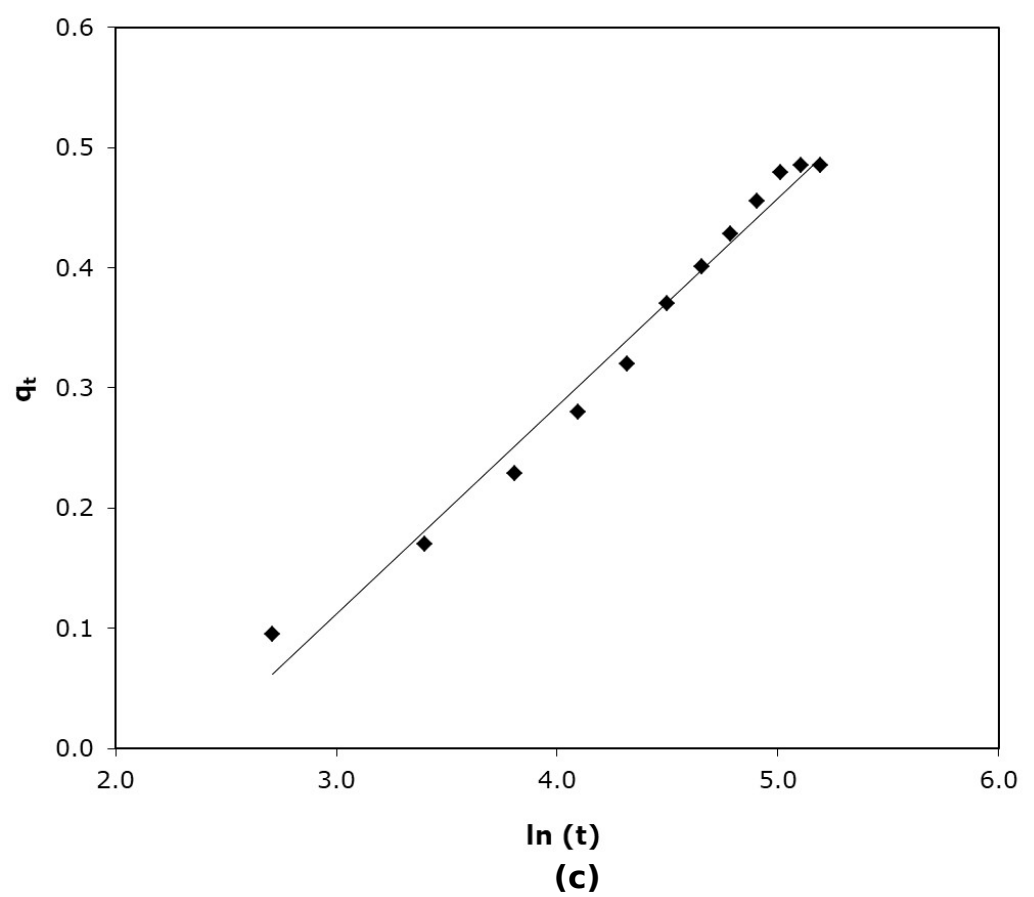

Figure 6 : Adsorption kinetics of itaconic acid by LDH at different temperatures, (a) Pseudo-first order equation; (b) Pseudo-second-order equation; (c) Elovich equation.

Tablo 4: Kinetic parameters for adsorption of itaconic acid by LDH ( $T=298 \mathrm{~K})$.

\begin{tabular}{ccccccccc}
\hline \multicolumn{2}{c}{ Pseudo-first-order } & \multicolumn{2}{c}{ Pseudo-second-order } & \multicolumn{3}{c}{ Elovich } \\
\hline$k_{1}$ & $q_{0}$ & $R^{2}$ & $k_{2}$ & $q_{e}$ & $R^{2}$ & $\alpha$ & $\beta$ & $R^{2}$ \\
\hline 0.0265 & 0.8841 & 0.8587 & 0.0105 & 0.8256 & 0.9919 & 0.016 & 5.78 & 0.9824 \\
\hline
\end{tabular}

When the $R^{2}$ values in Table 4 were evaluated, it was seen that the pseudo-second-order kinetic model was the most suitable kinetic model with a value of $\mathrm{R}^{2}=$ 0.9919 . This model shows that the adsorption of itaconic acid onto LDH is a chemisorption process $(38,39)$.

\section{CONCLUSIONS}

LDH was used to as an adsorbent to recover itaconic acid from aqueous solutions due to their high ion exchange capacity. In the study, the optimum adsorption time was determined and the effect of initial acid concentration, adsorbent amount, and temperature parameters on the adsorption capacity was investigated. The adsorption process and mechanism was revealed by analyzing the equilibrium and kinetic data after examining the parameters affecting the adsorption of itaconic acid onto $\mathrm{LDH}$. The maximum recovery efficiency was about $70 \%$ at the condition of $80.50 \mathrm{~g} \mathrm{~L}^{-1}$ initial acid concentration, $1 \mathrm{~g}$ of adsorbent, and $298 \mathrm{~K}$. When the isotherm results defining the chemical equilibrium process were examined, it was seen that all the isotherm models were fitted the equilibrium data. This result showed that the adsorption of itaconic acid by $\mathrm{LDH}$ was a monolayer process. It was revealed that the model specifying the kinetic process is the pseudo-second-order model with the highest regression coefficient $\left(R^{2}=0.9919\right)$. This work showed that LDH, a cheap and easily synthesis clay, can remove itaconic acid from the aqueous solutions. This study will also lead to further investigation of the adsorption behavior in the separation of itaconic acid from aqueous solutions using $\mathrm{LDH}$ with different $\mathrm{Mg} / \mathrm{Al}$ ratios.

\section{REFERENCES}

1. Willke T, Vorlop KD. Biotechnological production of itaconic acid. Appl Microbiol Biotechnol. 2001;56:289-95.

2. Kaur G, Elst K. Development of reactive extraction systems for itaconic acid: A step towards in situ product recovery for itaconic acid fermentation. RSC Adv. 2014; 4 (85): 45029-39.

3. Lalikoglu M, Bilgin M. Ternary phase diagrams for aqueous mixtures of butyric acid with several solvents: Experimental and correlated data. Fluid Phase Equilib. 2014;371:50-6.

4. Datta D, Aşçi YS, Tuyun AF. Extraction Equilibria of 
Glycolic Acid Using Tertiary Amines: Experimental Aliquat 336 in ethyl acetate, toluene, hexane, and Data and Theoretical Predictions. J Chem Eng Data. kerosene. Ind Eng Chem Res. 2011;50(2):1003-11. 2015;60(11):3262-7.

5. Baylan N, Çehreli S. Experimental and modeling study for the removal of formic acid through bulk ionic liquid membrane using response surface methodology. Chem Eng Commun. 2020; 207(10):1426-39.

6. Gemici A, Uslu H, Gök A, Kirbaşlar SI. Effect of diluents on the extraction of fumaric acid by tridodecyl amine (TDA). J Chem Eng Data. 2015;60(3):919-24.

7. López-Garzón CS, Straathof AJJ. Recovery of carboxylic acids produced by fermentation. Biotechnol Adv. 2014;32(5):873-904.

8. Carstensen F, Klement $\mathrm{T}$, Büchs J, Melin T, Wessling M. Continuous production and recovery of itaconic acid in a membrane bioreactor. Bioresour Technol. 2013; 137: 179-87.

9. Li A, Sachdeva S, Urbanus JH, Punt PJ. In-stream itaconic acid recovery from aspergillus terreus fedbatch fermentation. Ind Biotechnol. 2013;9(3):139-45.

10. Stodollick J, Femmer R, Gloede M, Melin T, Wessling M. Electrodialysis of itaconic acid: A shortcut model quantifying the electrical resistance in the overlimiting current density region. J Memb Sci. 2014;453:275-81.

11. Fidaleo M, Moresi M. Application of the NernstPlanck approach to model the electrodialytic recovery of disodium itaconate. J Memb Sci. 2010;349(1-2):393-404.

12. Dwiarti L, Otsuka M, Miura S, Yaguchi M, Okabe M. Itaconic acid production using sago starch hydrolysate by Aspergillus terreus TN484-M1. Bioresour Technol. 2007; 98 (17) :3329-37.

13. Hogle BP, Shekhawat D, Nagarajan K, Jackson JE, Miller DJ. Formation and recovery of itaconic acid from aqueous solutions of citraconic acid and succinic acid. Ind Eng Chem Res. 2002;41(9):206973.

14. Kreyenschulte D, Heyman B, Eggert A, Maßmann $T$, Kalvelage $C$, Kossack $R$, et al. In situ reactive extraction of itaconic acid during fermentation of Aspergillus terreus. Biochem Eng J. 2018;135:133-41.

15. Kumar S, Babu BV. Process Intensification for Separation of Carboxylic Acids from Fermentation Broths using Reactive Extraction. i-manager's J Futur Eng Technol. 2008;3(3):21-8.

16. Wasewar KL, Shende D, Keshav A. Reactive extraction of itaconic acid using quaternary amine
17. Bressler E, Braun S. Separation mechanisms of citric and itaconic acids by water-immiscible amines. J Chem Technol Biotechnol. 1999;74(9):891-896.

18. Aşçi YS, İnci I. A novel approach for itaconic acid extraction: Mixture of trioctylamine and tridodecylamine in different diluents. J Ind Eng Chem. 2012;18(5):1705-9.

19. Magalhães Al, de Carvalho JC, Medina JDC, Soccol CR. Downstream process development in biotechnological itaconic acid manufacturing. Appl Microbiol Biotechnol. 2017;101(1):1-12.

20. Magalhães Al, de Carvalho JC, Thoms JF, Medina JDC, Soccol CR. Techno-economic analysis of downstream processes in itaconic acid production from fermentation broth. J Clean Prod. 2019;206:336-48.

21. Pan B, Pan B, Zhang W, Lv L, Zhang Q, Zheng S. Development of polymeric and polymer-based hybrid adsorbents for pollutants removal from waters. Chem Eng J. 2009;151:19-29.

22. Gasser MS, Mohsen HT, Aly HF. Humic acid adsorption onto $\mathrm{Mg} / \mathrm{Fe}$ layered double hydroxide. Colloids Surfaces A Physicochem Eng Asp. 2008;331(3):195-201.

23. Zümreoglu-Karan B, Ay AN. Layered double hydroxides - Multifunctional nanomaterials. Chem Pap. 2012;66(1):1-10.

24. Das NN, Konar J, Mohanta MK, Srivastava SC. Adsorption of $\mathrm{Cr}(\mathrm{VI})$ and $\mathrm{Se}(\mathrm{IV})$ from their aqueous solutions onto $\mathrm{Zr} 4+$-substituted $\mathrm{ZnAl} / \mathrm{MgAl}$-layered double hydroxides: effect of $\mathrm{Zr} 4+$ substitution in the layer. J Colloid Interface Sci. 2004;270(1):1-8.

25. Centi G, Perathoner S. Catalysis by layered materials: A review. Microporous Mesoporous Mater. 2008;107(1):3-15.

26. Nedim Ay A, Konuk D, Zümreoglu-Karan B. Prolate spheroidal hematite particles equatorially belt with drug-carrying layered double hydroxide disks: Ring Nebula-like nanocomposites. Nanoscale Res Lett. 2011;6(1):116.

27. Ay AN, Zümreoglu-Karan B, Temel A. Boron removal by hydrotalcite-like, carbonate-free Mg-AlNO3-LDH and a rationale on the mechanism. Microporous Mesoporous Mater. 2007;98(1):1-5.

28. Gök A, Gök MK, Aşçı YS, Lalikoglu M. Equilibrium, kinetics and thermodynamic studies for separation of malic acid on layered double hydroxide (LDH). Fluid Phase Equilib. 2014 Jun;372:15-20. 
29. Gök A. Enhanced adsorption of nicotinic acid by different types of $\mathrm{Mg} / \mathrm{Al}$ layered double hydroxides: synthesis, equilibrium kinetics thermodynamics. J Dispers Sci Technol. 2020 Apr $15 ; 41(5): 779-86$.

30. Lalikoğlu M, Gök A, Gök MK, Aşçı YS. Investigation of Lactic Acid Separation by Layered Double Hydroxide: Equilibrium, Kinetics, and Thermodynamics. J Chem Eng Data. $2015 ; 60(11): 3159-65$.

31. Gulicovski Jl, Čerović LS, Milonjić SK, Popović IG. Adsorption of itaconic acid from aqueous solutions onto alumina. I Serbian Chem Soc. 2008;73(89):825-34.

32. Magalhães Al, De Carvalho JC, Ramírez ENM, Medina JDC, Soccol CR. Separation of Itaconic Acid from Aqueous Solution onto Ion-Exchange Resins. I Chem Eng Data. 2016;61(1):430-7.

33. Ladewig K, Niebert M, Xu ZP, Gray PP, Lu GQ (Max). Controlled preparation of layered double hydroxide nanoparticles and their application as gene delivery vehicles. Appl Clay Sci. 2010;48:280-9.

34. Özgümüş S, Gök $M K$, Bal A, Güçlü G. Study on novel exfoliated polyampholyte nanocomposite hydrogels based on acrylic monomers and $\mathrm{Mg}-\mathrm{Al}-\mathrm{Cl}$ layered double hydroxide: Synthesis and characterization. Chem Eng J. 2013;223:277-86.

35. Baylan N. Removal of levulinic acid from aqueous solutions by clay nano-adsorbents: equilibrium, kinetic, and thermodynamic data. Biomass Convers Biorefinery. 2020; In press.

36. Özcan Ö, Inci ì, Aşçi YS. Multiwall Carbon Nanotube for Adsorption of Acetic Acid. J Chem Eng Data. 2013;58(3):583-7.

37. Aşçı YS. Removal of textile dye mixtures by using modified $\mathrm{Mg}-\mathrm{Al}-\mathrm{Cl}$ layered double hydroxide (LDH). J Dispers Sci Technol. 2017;38(7):923-9.

38. Du B, Shan R, Yang K, Hao Y, Yan L. Adsorption of $\mathrm{Cd}(\mathrm{II})$ by $\mathrm{Mg}-\mathrm{Al}-\mathrm{CO} 3-$ and magnetic Fe3O4/Mg-AlCO3-layered double hydroxides: Kinetic, isothermal, thermodynamic and mechanistic studies. J Hazard Mater. 2015;299:42-9.

39. Rasoulpoor K, Poursattar Marjani A, Nozad E. Competitive chemisorption and physisorption processes of a walnut shell based semi-IPN biocomposite adsorbent for lead ion removal from water: Equilibrium, Kinetic and Thermodynamic studies. Environ Technol Innov. 2020; 20: 101133. 
Lalikoglu M. JOTCSA. 2021; 8(1): 103-116.

RESEARCH ARTICLE 